\title{
Review: atenolol may be ineffective for reducing cardiovascular morbidity or all cause mortality in hypertension
}

Carlberg B, Samuelsson O, Lindholm LH. Atenolol in hypertension: is it a wise choice? Lancet 2004;364:1684-9.

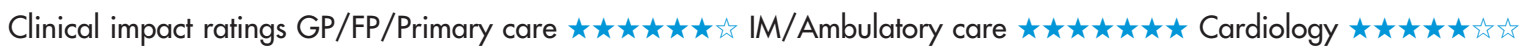

In patients with essential hypertension, does atenolol reduce cardiovascular morbidity or all cause mortality?

\section{METHODS}

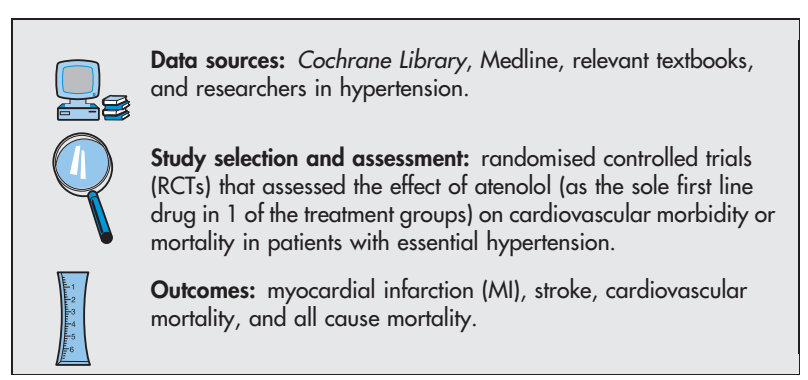

\section{MAIN RESULTS}

8 RCTs met the selection criteria. 2 major comparisons were made. Atenonol compared with placebo or with untreated controls (4 RCTs, $\mathrm{n}=6825)$. Mean reduction in blood pressure (BP) attributed to atenolol ranged from 4.0-18.0 mm $\mathrm{Hg}$ systolic and $2.9-11.0 \mathrm{~mm} \mathrm{Hg}$ diastolic. The groups did not differ for MI, stroke, cardiovascular mortality, or all cause mortality (table). Atenolol compared with other antihypertensive drugs (5 RCTs, $\mathrm{n}=17$ 671). Mean BP change with atenolol compared with alternatives ranged from -1.0 to $1.1 \mathrm{~mm} \mathrm{Hg}$ systolic and -1.0 to $0.5 \mathrm{~mm} \mathrm{Hg}$ diastolic. The rates of stroke, and cardiovascular and all cause mortality were greater in the atenolol group than in the other antihypertensive drug group (table). The groups did not differ for rates of MI (table).

\section{CONCLUSIONS}

In patients with essential hypertension, atenolol is not better than placebo or no treatment for reducing cardiovascular morbidity or all cause mortality. However, compared to other antihypertensive drugs, it may increase the risk of stroke or death.

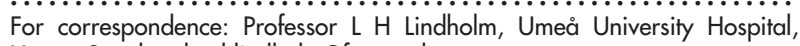
Umeå, Sweden. larshlindholm@fammed.umu.se

Source of funding: not stated
Abstract and commentary also appear in ACP Journal Club.

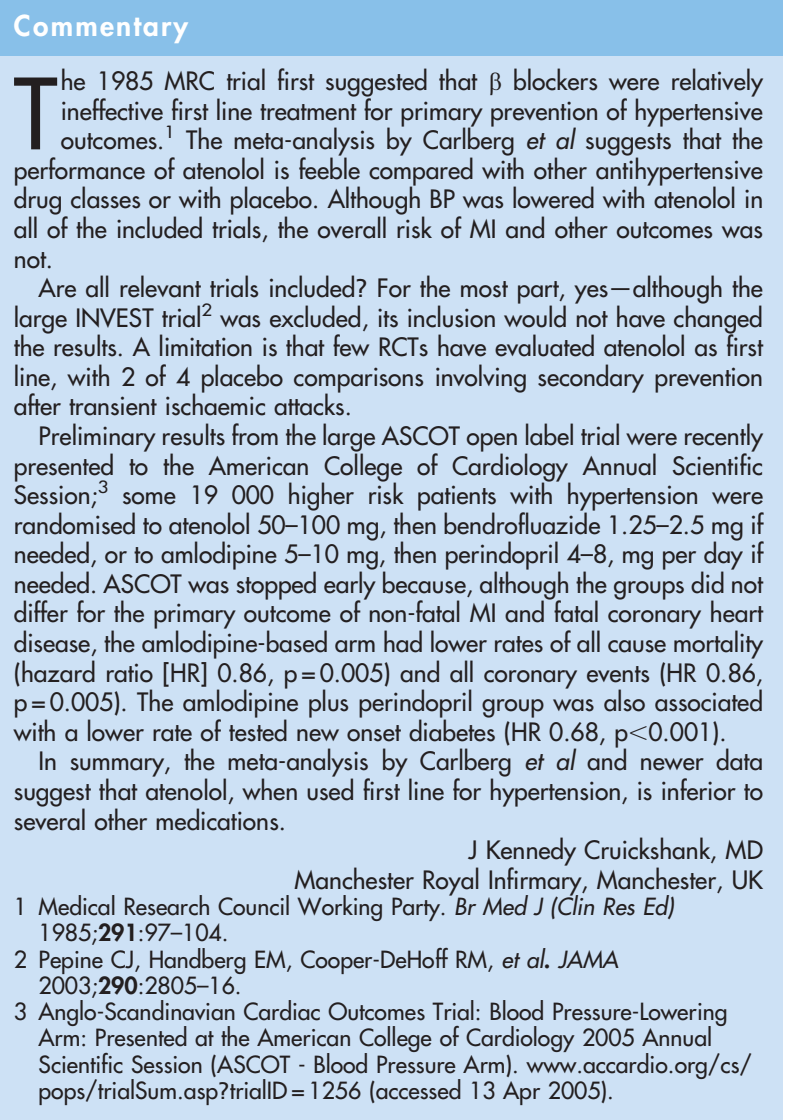

Atenolol $v$ placebo or no treatment or $v$ other antihypertensive drugs in essential hypertension at mean 4.6 years*

\begin{tabular}{|c|c|c|c|c|c|}
\hline Outcomes & Comparisons & $\begin{array}{l}\text { Number of trials } \\
\text { (number of patients) }\end{array}$ & Weighted event rates & $\operatorname{RRR}(95 \% \mathrm{Cl})$ & NNT \\
\hline \multirow{2}{*}{$\begin{array}{l}\text { Myocardial infarction } \\
\text { Stroke } \\
\text { Cardiovascular } \\
\text { mortality }\end{array}$} & $\begin{array}{l}\text { Atenolol } v \text { placebo or no } \\
\text { treatment }\end{array}$ & $4(6392)$ & $\begin{array}{l}7.2 \% \vee 7.2 \% \\
7.2 \% \vee 8.2 \% \\
8.0 \% \vee 8.0 \%\end{array}$ & $\begin{array}{l}1 \%(-19 \text { to } 17) \\
15 \%(-1 \text { to } 28) \\
1 \%(-18 \text { to } 17)\end{array}$ & $\begin{array}{l}\text { Not significant } \\
\text { Not significant } \\
\text { Not significant }\end{array}$ \\
\hline & & & & RRI (CI) & NNH (Cl) \\
\hline $\begin{array}{l}\text { All cause mortality } \\
\text { Myocardial infarction } \\
\text { Stroke } \\
\text { Cardiovascular mortality } \\
\text { All cause mortality }\end{array}$ & $\begin{array}{l}\text { Atenolol } v \text { other } \\
\text { antihypertensive drugs }\end{array}$ & $4(14468)$ & $\begin{array}{l}13.3 \% \vee 13.3 \% \\
4.5 \% \vee 4.5 \% \\
5.2 \% \vee 4.2 \% \\
5.4 \% \vee 4.4 \% \\
8.1 \% \vee 7.1 \%\end{array}$ & $\begin{array}{l}1 \%(-11 \text { to } 15) \\
4 \%(-11 \text { to } 20) \\
30 \%(12 \text { to } 50) \\
16 \%(0 \text { to } 34) \\
13 \%(2 \text { to } 25)\end{array}$ & $\begin{array}{l}\text { Not significant } \\
\text { Not significant } \\
100(50 \text { to } 100) \\
100(100 \text { to } \infty) \\
100(100 \text { to } \infty)\end{array}$ \\
\hline
\end{tabular}

*Abbreviations defined in glossary; weighted event rates, RRR, RRI, NNT, NNH, and Cl calculated from data in article using a fixed effects model. 